\title{
PERCEPÇÃO DE MULHERES SOBRE O ACOLHIMENTO OFERECIDO PELO ENFERMEIRO NO PRÉ-NATAL*
}

\author{
Ricardo Saraiva Aguiar1, Maria Aparecida Batista de Araújo², Marli Aparecida Costa², \\ Nicoly Aguiar ${ }^{3}$
}

RESUMO: O objetivo deste estudo foi analisar a percepção das gestantes sobre o acolhimento oferecido pelo enfermeiro em Unidade Básica de Saúde. Trata-se de estudo descritivo e de abordagem qualitativa com a participação de 14 gestantes cadastradas em uma unidade de saúde de Gurupi-Tocantins. Utilizou-se um roteiro de entrevista semiestruturada e os resultados foram submetidos à análise de conteúdo; o estudo foi aprovado por Comitê de Ética. Os resultados demonstram que as gestantes identificaram, no atendimento do enfermeiro, receptividade e orientações sobre o pré-natal e procedimentos necessários ao momento.

DESCRITORES: Acolhimento; Cuidado Pré-natal; Enfermagem; Qualidade da assistência à saúde.

\section{WOMEN'S PERCEPTION ON THE EMBRACEMENT OFFERED BY THE NURSE IN THE PRE-NATAL CHECK-UP}

\begin{abstract}
This study's objective was to analyze the perception of pregnant women on the embracement provided by the nurse in the Primary Health Centers. It is a descriptive study with a qualitative approach, undertaken with the participation of 14 pregnant women registered at a health center in Gurupi-Tocantins. It used a semi-structured interview script, and the results were submitted to content analysis; the study was approved by the Ethics Committee. The results demonstrate that the pregnant women identified, in the nurse's attendance, receptivity and guidance on the pre-natal consultation and the procedures necessary at the time. DESCRIPTORS: Embracement; Pre-natal care; Nursing; Quality of health care.
\end{abstract}

\section{PERCEPCIÓN DE MUJERES ACERCA DEL ACOGIMIENTO OFRECIDO POR EL ENFERMERO EN PRENATAL}

RESUMEN: El objetivo de este estudio fue analizar la percepción de las gestantes acerca del acogimiento prestado por el enfermero en Unidad Básica de Salud. Es un estudio descriptivo y de abordaje cualitativo con la participación de 14 gestantes registradas en una unidad de salud de Gurupi-Tocantins. Fue utilizado un guion entrevista semiestructurada y los resultados fueron sometidos al análisis de contenido; el estudio fue aprobado por Comité de Ética. Los resultados muestran que las gestantes identificaron, en el atendimiento del enfermero, receptividad y orientaciones sobre el prenatal y procedimientos necesarios al momento.

DESCRIPTORES: Acogimiento; Cuidado Prenatal; Enfermería; Cualidad de la asistencia a la salud. *Artigo elaborado a partir do Trabalho de Conclusão de Curso “A percepção das gestantes em relação às orientações prestadas pelo
enfermeiro durante o pré-natal de baixo risco", apresentado ao Centro Universitário de Gurupi - Tocantins em 2011.

${ }^{1}$ Enfermeiro do Núcleo de Saúde da Criança da Secretaria de Estado da Saúde do Distrito Federal. Especialista em Saúde da Família. ${ }^{2}$ Enfermeira.

${ }^{3}$ Enfermeira. Professora e Coordenadora do Curso de Graduação em Enfermagem do Centro Universitário de Gurupi - Tocantins. 


\section{INTRODUÇÃO}

A atenção obstétrica foi reconhecida como uma área prioritária no Brasil a partir da promulgação da Política Nacional de Atenção Integral à Saúde da Mulher, pelo Ministério da Saúde, com a ampliação das ações e garantia de atenção voltada às necessidades da população feminina em seu ciclo de vida ${ }^{(1)}$.Neste contexto, a gestação, embora constituindo um fenômeno fisiológico, em sua maioria, com evolução sem intercorrências, requer cuidados especiais mediante assistência pré-natal. Essa, por sua vez, tem como objetivo principal acolher e acompanhar a mulher durante sua gestação, período caracterizado por mudanças físicas e emocionais, e vivenciado de forma distinta ${ }^{(2)}$.

Dessa forma, o acolhimento no pré-natal constitui-se no primeiro contato da mulher, com o profissional de saúde, na maioria das situações o enfermeiro. Nesse momento, a mulher deve ser orientada sobre o acompanhamento, periodicidade das consultas na unidade e procedimentos recomendados para aquele momento, além de retirar suas dúvidas e expressar angústias e sentimentos.

Observa-se que, no Brasil, ainda é muito forte a representação social das gestantes sobre o processo gestacional como um fenômeno natural, o que pode contribuir para a falta de cuidado na gravidez, não aderência e evasão do pré-natal, e culminar em alta incidência de distúrbios gestacionais graves ${ }^{(3)}$. Nesse sentido, o acolhimento oferecido no início do pré-natal é uma iniciativa de suma importância, pois tem a finalidade de receber a mulher na unidade de saúde e dar um seguimento a sua atenção. É requerido do profissional, além da competência técnica, sensibilidade para compreender o ser humano e o seu modo de vida, e habilidade de comunicação, baseada na escuta e na ação dialógica( ${ }^{(4)}$.

Neste contexto, este estudo justifica-se pela necessidade do enfermeiro em conhecer as percepções das gestantes sobre o acolhimento oferecido por ele nas unidades de saúde, para que possa compreender como poderá implementar ações que fortaleçam a atenção pré-natal. Portanto, buscou-se analisar as percepções das gestantes a respeito do acolhimento oferecido pelo enfermeiro em uma Unidade Básica de Saúde (UBS) e espera-se que os resultados apresentados subsidiem a qualidade da atenção à saude.

\section{MÉTODO}

Trata-se de estudo descritivo e de abordagem qualitativa realizado em uma UBS no Município de Gurup-
-Tocantins entre os meses de março e abril de 2011. O Município está localizado na região sul do Estado do Tocantins e possuía uma população de 76.765 habitantes. Foram participantes desta pesquisa 14 gestantes que atenderam aos seguintes critérios de inclusão: estar classificada como gestação de baixo risco; frequentar regularmente as consultas de enfermagem no pré-natal e ter mais de 18 anos de idade. Todas participantes aceitaram livremente em participar e formalizaram o aceite por meio da assinatura do Termo de Consentimento Livre e Esclarecido.

$\mathrm{Na}$ coleta de dados optou-se pelo emprego de entrevista semiestruturada contendo questões de identificação pessoal e questões abertas para discorrer livremente sobre o tema proposto. Adotaram-se as seguintes questões norteadoras neste estudo: Como foi o primeiro atendimento do enfermeiro da unidade de saúde após o resultado do exame de gravidez? Quais orientações você recebeu nesse atendimento?

As entrevistas foram realizadas durante visita domiciliar, após a autorização das gestantes. Para garantir o anonimato, as participantes foram identificadas pela letra " $G$ " e o respectivo número da ordem cronológica da entrevista. O registro das entrevistas se deu por meio das respostas gravadas seguida de transcrição na íntegra.

O processo de explicitação, sistematização e expressão do conteúdo das mensagens foi realizado em três etapas realizadas em conformidade com três pólos cronológicos diferentes: a pré-análise, a exploração do material e o tratamento dos resultados obtidos e interpretação ${ }^{(5)}$.

A pesquisa foi avaliada e aprovada pelo Comitê de Ética em Pesquisa do Centro Universitário de Gurupi sob parecer n. 0202/2010 e autorizada pela Secretaria Municipal de Saúde de Saúde. Todos os procedimentos metodológicos obedeceram aos padrões estabelecidos pela pelas Normas de Pesquisa Envolvendo Seres Humanos.

\section{RESULTADOS}

As participantes tinham idade superior a 19 e inferior a 40 anos; a maioria era casada (11 mulheres) e três eram solteiras; no que se refere à escolaridade, 8 gestantes tinham o ensino médio completo, quatro o ensino superior, uma o ensino médio incompleto e uma o ensino fundamental.

Nos depoimentos, conforme exemplos das falas a seguir, a maioria das gestantes explicitaram que o acolhimento oferecido pelo enfermeira foi considerado como bom. 
Foi bem. Eu fui muito bem recebida e ela [enfermeira] tratou a gente bem e orientou direitinho. (G3)

Foi muito boa. Ela [enfermeira] tirou muitas dúvidas que eu tinha. Explicou tudo direitinho, o que era o pré-natal e o quê que era para eu fazer. (G5)

Contudo, verificou-se que duas gestante sentiram-se insatisfeitas com o atendimento oferecido na unidade de saúde devido à enfermeira não ter abordado temas referentes ao pré-natal, e sim dado atenção ao preenchimento dos documentos necessários ao cadastro da gestante no programa SIS Pré-natal, bem como para a solicitação dos exames complementares, como observa-se:

Ela ficou mais preenchendo papel do que falando comigo mesmo, esódepois meentregouopedido dos exames. (G13)

Ela não falou quase nada, só passou os exames e preencheu os papéis. (G14)

As gestantes referiram alguns procedimentos e orientações realizados pelo enfermeiro durante $o$ acolhimento, como se percebe nos depoimentos:

A enfermeira pediu um monte de exames. Ela explicou como é que deveriam ser realizados os exames e falou a importância deles, mas eu não lembro qual é a importância deles não. (G1)

Ela pediu os exames que tem que fazer, ai pegou todos os meus dados para fazer o cartão da gestante e explicou tudo o que tem que fazer durante a gestação. $(\mathrm{G} 2)$

Ela [enfermeira] falou para eu continuar fazendo o acompanhamento do pré-natal para o bebê nascer bem. (G6)

Ela [enfermeira] orientou sobre alimentação e outras tantas coisas. (G10)

Ela falou dos exames que ia solicitar, preencheu e me entregou o cartão da gestante e que em todo atendimento eu deveria estar com ele e disse ainda sobre a alimentação. (G11)

\section{DISCUSSÃO}

As mulheres tem sido cada vez mais estimuladas a manter o acompanhamento rotineiro do pré-natal, de- positam confiança e entregam seus corpos aos cuidados de profissionais de saúde. Dessa forma, o acolhimento constitui ferramenta primordial para a efetivação da assistência pré-natal, e representa o primeiro contato da mulher gestante com o serviço de saúde.

Acolher significa dar acolhida a, dar agasalho a, dar crédito a, dar ouvidos a; admitir, aceitar, receber; e tomar em consideração ${ }^{(6)}$. O acolhimento implica na recepção da mulher, desde sua chegada na unidade de saúde, responsabilizando-se por ela, ouvindo suas queixas, permitindo que essa expresse preocupações e angústias e, dessa forma, garantindo atenção resolutiva e articulação com os outros serviços de saúde ${ }^{(7)}$.

Nesse contato, a gestante deverá receber informações sobre o acompanhamento do pré-natal na unidade de saúde, tendo a possibilidade de conhecer o plano de ação das consultas subsequentes, tirar suas dúvidas e expressar suas opiniões. Nessa oportunidade deve ser fornecido o cartão da gestante, devidamente identificado e preenchido; as solicitações dos exames complementares, segundo o protocolo assistencial aprovado pela instituição de saúde; recomendações de vacinas; orientações diversas sobre atividades profissionais, físicas, educativas, visitas domiciliares, entre outras ${ }^{(8)}$.

O enfermeiro deve aproxima-se de cada gestante, respeitando suas singularidades e não perdendo de vista o seu contexto social e familiar de forma a estabelecer um diálogo franco. Deste modo, ouvir atentamente sem julgamentos, respeito, ser empático, apresentar tolerância, disponibilidade, confiança, diálogo e preservar a individualidade do outro e a troca de experiências se faz necessários a fim de que o cuidado repercuta não só na qualidade dos sentimentos manifestos pela mulher, mas também que culmine em adequação saudável da gestante ao seu papel materno ${ }^{(9)}$.

A mulher ao entrar em uma unidade de saúde pode apresentar dúvidas em relação à gravidez, pois pode ser algo desconhecido para ela. A gravidez é um período crítico de transição do desenvolvimento da personalidade e também um período de tensão biologicamente determinado, caracterizado por mudanças metabólicas de novas adaptações. Dessa forma, cabe ao enfermeiro favorecer a integração dela ao pré-natal de modo que se sinta segura, informada e orientada quanto a tudo o que estiver acontecendo; é relevante que o profissional busque compreender os múltiplos significados da gestação para a mulher e para sua família ${ }^{(10)}$.

A enfermagem vem conquistando um espaço importantíssimo no que se diz respeito à assistência durante o pré-natal. De acordo com a Lei do Exer- 
cício $^{(11)}$, com o Decreto n. $94.406 / 87^{(12)}$ e com as recomendações do Ministério da Saúde ${ }^{(7)}$, o pré-natal de baixo risco pode ser inteiramente acompanhado pelo enfermeiro. Baseado nisso, cabe ao profissional realizar consulta de enfermagem e a prescrição da assistência de enfermagem. Como integrante da equipe de saúde, o enfermeiro pode prescrever medicamentos e solicitar exames estabelecidos em protocolos assistenciais aprovados pela instituição de saúde ${ }^{(11)}$.

Nesse sentido, o enfermeiro deve proporcionar ações para que a mulher adquira autonomia no agir, aumentando sua capacidade de enfrentar situações de estresse e de crise e decida sobre sua vida e sua saúde. Pois a gravidez é um dos momentos na vida da mulher, em que ela vivencia uma gama de sentimentos que, se desejada, traz alegria, se não esperada pode gerar surpresa, tristeza e, até mesmo, negação. Ansiedade e dúvidas com relação às modificações pelas quais vai passar e sobre como a criança está se desenvolvendo são também sentimentos comuns presentes na gestante $^{(4)}$. Dessa forma, torna-se necessário atentar para o desenvolvimento de habilidades por parte do enfermeiro, não só no agir, mas também no escutar e no sentir ${ }^{(13)}$.

Diante disso, o acolhimento é o aspecto essencial da política de humanização e se inicia com a recepção da mulher na unidade de saúde. Neste contexto o profissional deve estimular que a gestante fale de suas preocupações e angústias e, dessa forma, deve responsabilizar-se por ela, garantindo a resolução de suas queixas ${ }^{(10)}$.

Portanto, o acolhimento, no início da assistência pré-natal, é um momento importantíssimo na vida da gestante, pois permite ao enfermeiro discutir e esclarecer, de forma individualizada, questões que são únicas para cada mulher, e garantir a adesão e vinculação dessa ao serviço de saúde.

\section{CONSIDERAÇÕES FINAIS}

Este estudo analisou a percepção das gestantes a respeito do acolhimento oferecido pelo enfermeiro em uma Unidade Básica de Saúde. Verificou-se que o acolhimento é mais do que receber a gestante no serviço. Ele permite que a mulher expresse suas opiniões, angústias e preocupações garantindo, assim, atenção resolutiva.

Diante disso, o acolhimento deve ser estimulado na atenção pré-natal para que a mulher adquira autonomia durante a gestação e no seu agir para que possa ser capaz de enfrentar as situações vivenciadas neste período. Além de promover a autonomia da mulher através do acolhimento, o enfermeiro também deve garantir a resolução das queixas durante a assistência oferecida.

Foi identificado no estudo que o acolhimento o foi receptivo como relataram a maioria das gestantes, as quais foram orientadas, cadastradas e encaminhadas de acordo com o período gestacional. Portanto, do ponto de vista pragmático, espera-se contribuir de forma significativa no incentivo a realização do acolhimento nas unidades de saúde para que se possa continuamente promover a qualidade da assistência oferecida às mulheres na atenção pré-natal.

\section{REFERÊNCIAS}

1. Ohara ECC, Saito RXS. Saúde da família: considerações teóricas e aplicabilidade. São Paulo: Martinari; 2008.

2. Landerdahl MC, Ressel LB, Martins FB, Bheregaray F, Gonçalves MO. A percepção de mulheres sobre a atenção pré-natal em uma unidade básica de saúde. Esc Anna Nery. 2007;11(1):105-11.

3. Shimuzu HE, Lima MG. As dimensões do cuidado prénatal na consulta de enfermagem. Rev. bras. enferm. 2009;62(3):387-92.

4. Rios CTF, Vieira NFC. Ações educativas no pré-natal: reflexão sobre a consulta de enfermagem como um espaço para a educação em saúde. Ciênc. saúde colet. 2007;12(2):477-86.

5. Minayo MCS. O desafio do conhecimento: pesquisa qualitativa em saúde. $7^{\mathrm{a}}$ ed. São Paulo: Hucitec; 2000.

6. Dicionário Aurélio de língua portuguesa. $5^{\mathrm{a}} \mathrm{ed}$. Rio de Janeiro: Positivo; 2010. Acolhimento; p. 115.

7. Ministério da Saúde (BR). Secretaria de Atenção à Saúde. Pré-natal e puerpério: atenção qualificada e humanizada. Brasília: Ministério da Saúde; 2005.

8. São Paulo, Secretaria da Saúde, Coordenadoria de Planejamento em Saúde, Assessoria Técnica em Saúde da Mulher. Atenção à gestante e à puérpera no SUS-SP: manual técnico do pré-natal e puerpério. São Paulo: Secretaria da Saúde; 2010.

9. Melo MCP, Dourado CP, Silva AMP, Santos RAA, Santos ALS. Nursing consultation in the pre-natal: women's voice. Rev. enferm UFPE on line. 2011;5(2) [acesso em 22 mai 2013]. Disponível: http://www. revista.ufpe.br/revistaenfermagem/index.php/revista/ article/view/1589. 
10. Lessa R, Rosa AHV. Enfermagem e acolhimento: a importância da interação dialógica no pré-natal. Rev. pesqui. cuid. fundam. online 2010;2(3) [acesso em 22 mai 2013]. Disponível: http://www.seer.unirio.br/index. php/cuidadofundamental/article/view/631/pdf_49.

11. Brasil. Lei $n^{\circ} 7.498$ de 25 de junho de 1986. Dispõe sobre o exercício da enfermagem e dá outras providências. Brasília: Senado Federal; 1986.

12. Brasil. Decreto n. 94.406 de 08 de junho de 1987. Regulamenta a Lei n. 7.498 de 25 de junho de 1986, que dispõe sobre o exercício da enfermagem e dá outras providências. Brasília: Senado Federal; 1987.

13. Camillo SO, Maiorino FT. A importância da escuta no cuidado de enfermagem. Cogitare enferm. 2012;17(3):549-55. 